\title{
Pemberdayaan Masyarakat Melalui Pengolahan Singkong menjadi Bahan Baku Produk Olahan Makanan di Desa Tarung Manuah, Kecamatan Basarang, Kabupaten Kapuas
}

\section{Community Empowerment through Processing Cassava into Raw Materials for Processed Food Products in Tarung Manuah Village, Basarang District, Kapuas Regency}

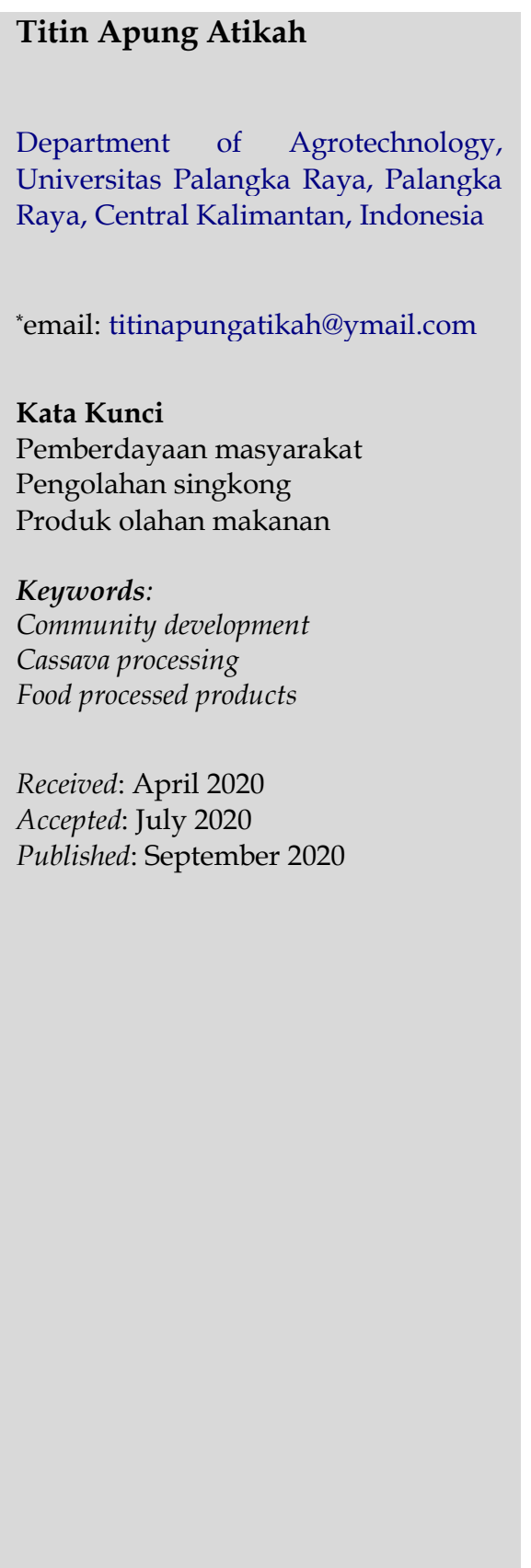

\begin{abstract}
Abstrak
Ubi kayu atau singkong merupakan jenis tanaman yang mudah tumbuh diberbagai jenis tanah serta cara budidayanya relatif mudah. Bagian batang, daun dan umbi singkong memiliki berbagai manfaat bagi kehidupan manusia. Keterbatasan pengetahuan dan ketrampilan tentang diversifikasi produk olahan berbasis singkong menjadi kendala yang harus dicari solusinya. Tujuan kegiatan pengabdian ini adalah untuk memberdayakan masyarakat khususnya mitra/kelompok sasaran melalui pelatihan pengolahan singkong menjadi bahan baku produk olahan makanan. Kegiatan pengabdian yang dilakukan dengan metode pelatihan/pendampingan serta demontrasi/praktek menjadi salah satu solusi yang dapat dilakukan untuk pemberdayaan masyarakat. Hasil kegiatan pengabdian didapatkan data bahwa semua peserta $(100 \%)$ turut aktif dapat menerima semua pengetahuan dan ketrampilan yang ditransfer dan berminat melakukan sendiri dirumah (100\%), dimana produk olahan berupa tepung singkong akan dikonsumsi sendiri $(77 \%)$ dan dijual (23\%) dengan produk olahan makanan dodol singkong (89\%) dan mie cassava (11\%) yang diminati. Data tersebut menunjukkan bahwa kegiatan pengabdian kepada masyarakat yang dilakukan oleh Universitas Palangka Raya mampu berkontribusi dan menjadi solusi untuk mengatasi permasalahan yang dihadapi masyarakat.
\end{abstract}

\begin{abstract}
Cassava is a type of plant that is easy to grow in various types of soil, and its cultivation method is relatively easy. The stems, leaves, and tubers of cassava have various benefits for human life. Limited knowledge and skills regarding the diversification of cassava-based processed products are an obstacle for which solutions must be sought. The purpose of this service activity is to empower the community, especially partners/target groups, through training on processing cassava into raw materials for processed food products. Community service activities carried out using training/mentoring and demonstrations/practices are one of the solutions that can be carried out for community empowerment. The results of community service activities show that all participants $(100 \%)$ can actively participate in receiving all the knowledge and skills transferred and are interested in doing it themselves at home $(100 \%)$. Processed products in the form of cassava flour will be consumed by themselves (77\%) and sold (23\%) with processed food products of cassava lunkhead $(89 \%)$ and cassava noodles $(11 \%)$, which were of high interest. This data shows that community service activities carried out by Palangka Raya University can contribute and become a solution to overcome problems faced by the community.
\end{abstract}




\section{PENDAHULUAN}

Tarung Manuah merupakan salah satu desa yang berada di wilayah kecamatan Basarang, kabupaten Kapuas. Kecamatan Basarang terletak di Daerah Aliran Sungai Kapuas, dimana merupakan kawasan agropolitan yang telah menghasilkan berbagai produk pertanian maupun peternakan (Pemerintah Kabupaten Kapuas, 2017). Desa Tarung Manuah adalah daerah dengan pemukiman penduduk yang masih belum terlalu padat dengan luasan pekarangan masing-masing keluarga cukup luas. Desa ini merupakan salah satu desa yang potensial dari segi lokasi maupun ketersediaan dan kesuburan lahannya.

Ada bermacam tanaman pertanian yang ditanam masyarakat dimana dapat tumbuh dan beradaftasi dengan kondisi lingkungan setempat (Atikah et al., 2019). Tanaman ubi kayu atau singkong merupakan salah satu tanaman yang adaptif dan banyak dibudidayakan masyarakat. Pada tahun 2015, luas panen ubi kayu sebesar 565 ha dengan produksi 7.832 ton dengan ratarata produksi 138,62 kg/ha (Badan Pusat Statistik Provinsi Kalimantan Tengah, 2019). Hal ini menunjukan bahwa tanaman singkong merupakan komoditas yang cukup potensial didaerah ini.

Budidaya singkong yang relatif mudah, menjadikan tanaman ini hampir tidak ditemui kendala didalam pengusahaanya dilapangan (Nugraha et al., 2015). Namun pemanfaatan hasilnya masih terbatas hanya sebagai pangan tradisional yang diolah secara sederhana dan sebagian lagi hasil panen singkong dijual langsung ke konsumen atau ke pasar dengan harga yang relatif murah (Rosmiati et al., 2018). Hal ini menunjukkan peluang melakukan diversifikasi produk olahan singkong menjadi makanan olahan yang bernilai ekonomis belum banyak dilakukan (Mulyatun, 2019).

Berbagai permasalahan yang dihadapi mitra/kelompok sasaran dilokasi kegiatan yaitu Hasil singkong yang berlimpah namun dijual dalam bentuk segar dengan harga relatif murah; Kualitas produk olahan singkong yang dihasilkan mitra/kelompok sasaran masih tergolong rendah dan sederhana; dan Terbatasnya pengetahuan dan ketrampilan mitra/kelompok sasaran dalam hal teknologi diversifikasi produk olahan singkong dan masih belum ada pelatihan tentang pengolahan singkong menjadi produk olahan makanan (Muntoha, 2015; Santoso et al., 2015). Berdasarkan hasil wawancara dengan beberapa mitra/kelompok sasaran mereka menghendaki adanya peningkatan pengetahuan dan ketrampilan tentang teknologi sederhana pengolahan hasil singkong menjadi bahan baku produk olahan yang dapat disimpan lama, dapat diolah menjadi produk makanan yang lebih variatif dan memiliki nilai ekonomis agar pendapatan dan kesejahteraan mitra/kelompok sasaran dapat ditingkatkan (Ginting, 2002).

Adanya kegiatan pengabdian kepada masyarakat ini bertujuan untuk memberdayakan masyarakat khususnya mitra/kelompok sasaran melalui pelatihan pengolahan singkong menjadi bahan baku produk olahan makanan. Teknologi sederhana pengolahan singkong menjadi bahan baku produk olahan makanan merupakan salah satu bentuk kegiatan yang dilakukan agar terjadi peningkatan pengetahuan, ketrampilan dan inovasi melalui diversifikasi produk sekaligus meningkatan kualitas maupun nilai ekonomis produk berbasis singkong serta peningkatan pendapatan maupun kesejahteraan mitra/kelompok sasaran (Sutama et al., 2015).

\section{METODOLOGI}

Kegiatan pengabdian kepada masyarakat dilaksanakan selama tiga bulan. Berlokasi di desa Tarung Manuah, Kecamatan Basarang, Kabupaten Kapuas, Propinsi Kalimantan Tengah. Jarak antara Universitas Palangka 
Raya dengan lokasi $\pm 200-202 \mathrm{Km}$ dengan sarana transportasi dan komunikasi cukup lancar dimana akses jalan dapat ditempuh dengan menggunakan mobil dan kendaraan bermotor. Bahan yang digunakan adalah Umbi singkong segar, garam, tepung singkong, kelapa parut, gula merah, tepung terigu, minyak goreng, Kalium bikarbonat, $\mathrm{CMC}$, air bersih dan plastik kemasan. Alat yang digunakan adalah kamera, timbangan ember, beskom, saringan kelapa, kuali, panci serta peralatan lain yang menunjang kegiatan.

Metode pelaksanaan kegiatan dilakukan melalui pelatihan/pendampingan sekaligus mempraktekan teknologi sederhana pengolahan singkong menjadi bahan baku produk olahan makanan. Pelaksanaan kegiatan ini dilakukan oleh dua kelompok ibu-ibu (mitra 1 dan 2) yang masing-masing terdiri 7-8 orang anggota kelompok. Selain sebagai peserta pelatihan, keterlibatan mitra/kelompok pada persiapan sebelum kegiatan ini dilaksanakan diantaranya adalah menentukan jenis/produk tanaman apa yang akan diolah, menentukan peserta/mitra yang akan mengikuti kegiatan, menentukan tempat dan waktu pelaksanaan kegiatan serta berkoordinasi dengan pemangku dan instansi terkait di wilayah setempat. Langkah pelaksanaan kegiatan yang dilakukan sesuai kesepakatan bersama untuk mengatasi permasalahan mitra/kelompok sasaran adalah:

1. Peningkatan pengetahuan mitra/sasaran melalui pelaksanaan kegiatan penyuluhan tentang budidaya, manfaat serta kandungan nutrisi daun, batang maupun umbi tanaman singkong (Rukmana, 1997).

2. Kegiatan difusi ipteks yaitu melalui pelaksanaan pelatihan dan demonstrasi tentang cara pengolahan umbi singkong menjadi bahan produk olahan makanan seperti tepung singkong, dodol singkong, maupun mie cassava (Fardhayanti et al., 2019).
3. Melaksanakan pendampingan/praktek/demontrasi pengolahan dan pengemasan produk yang dilakukan secara langsung oleh peserta/mitra dengan tetap didampingi oleh pelatih, hal ini dilakukan agar para peserta lebih terampil dan dapat melakukan sendiri dirumah.

Peran pihak Kelurahan dalam hal ini lurah menyambut baik program kegiatan pengabdian yang dilaksanakan oleh pihak kampus. Hal ini dibuktikan dengan bersedianya lurah untuk mendampingi secara langsung pelaksanaan kegiatan dilapangan sehingga kegiatan yang dilaksanakan lebih terarah dan memberikan dampak positif bagi masyarakat.

Evaluasi kegiatan dilakukan pada akhir kegiatan dimana mitra/kelompok sasaran diwajibkan mengisi kuisioner yang telah disiapkan. Hal ini dilakukan untuk melihat tolak ukur keberhasilan melalui kepuasan dan tingkat kemandirian mitra setelah dilaksanakan kegiatan tersebut. Selain itu, indikator keberhasilan juga dapat dilihat dari meningkatnya pengetahuan dan ketrampilan peserta/mitra tentang materi pelatihan dan pengolahan yang disampaikan.

\section{HASIL DAN PEMBAHASAN}

Kegiatan Pelatihan Pengolahan Singkong menjadi bahan baku produk olahan makanan ini terdiri dari beberapa tahapan yaitu tahap persiapan, tahap pelaksanaan dan tahap evaluasi. Adapun uraian dari masing-masing tahapan kegiatan disajikan sebagai berikut:

\section{Tahap persiapan}

Sebelum dilakukan pelatihan peserta/mitra diberikan kuisioner yang datanya disajikan pada Tabel I.

Tabel I. Kuisioner dan jawaban sebelum kegiatan

\begin{tabular}{clccc}
\hline No & \multicolumn{2}{c}{ Pertanyaan } & \multicolumn{3}{c}{ Jawaban (\%) } \\
\hline 1. & Apakah ibu & Sudah & Belum & Tidak \\
& sdh pernah & $(100)$ & $(0)$ & tahu \\
& mengolah/ & & & $(0)$ \\
& memasak & & & \\
singkong? & & & \\
\hline
\end{tabular}




\begin{tabular}{|c|c|c|c|c|}
\hline 2. & $\begin{array}{l}\text { Singkong } \\
\text { diolah menjadi } \\
\text { apa? }\end{array}$ & $\begin{array}{c}\text { Kue } \\
\text { tradisional } \\
(90)\end{array}$ & $\begin{array}{l}\text { Kue } \\
\text { modern } \\
(10)\end{array}$ & $\begin{array}{l}\text { Lainnya } \\
\text { (0) }\end{array}$ \\
\hline 3. & $\begin{array}{l}\text { Darimana } \\
\text { ibu/saudara } \\
\text { mendapatkan } \\
\text { atau } \\
\text { memperoleh } \\
\text { singkong } \\
\text { selama ini? }\end{array}$ & $\begin{array}{c}\text { Membeli } \\
(11,11)\end{array}$ & $\begin{array}{c}\text { Menanam } \\
\text { sendiri } \\
(88,89)\end{array}$ & $\begin{array}{l}\text { Lainnya } \\
\quad(0)\end{array}$ \\
\hline 4. & $\begin{array}{l}\text { Berapa kali } \\
\text { memasak atau } \\
\text { makan olahan } \\
\text { dari singkong? }\end{array}$ & $\begin{array}{l}\text { Setiap hari } \\
(0)\end{array}$ & $\begin{array}{l}\text { Seminggu } \\
\text { sekali (75) }\end{array}$ & $\begin{array}{l}\text { Sebulan } \\
\text { sekali } \\
(25)\end{array}$ \\
\hline 5. & $\begin{array}{l}\text { Pernahkah } \\
\text { ibu/saudara } \\
\text { memperoleh } \\
\text { penyuluhan } \\
\text { tentang cara } \\
\text { pengolahan } \\
\text { singkong } \\
\text { menjadi } \\
\text { produk } \\
\text { olahannya? }\end{array}$ & $\begin{array}{l}\text { Belum } \\
(100)\end{array}$ & $\begin{array}{l}\text { Pernah } \\
\quad(0)\end{array}$ & $\begin{array}{c}\text { Tidak } \\
\text { tahu } \\
(0)\end{array}$ \\
\hline
\end{tabular}

Tabel I menunjukkan bahwa ibu-ibu mitra/kelompok sasaran di desa Tarung Manuah semuanya sudah pernah mengolah atau memasak singkong namun sebagian besar hanya diolah menjadi makanan tradisional seperti kue-kue basah, gorengan bahkan hanya direbus saja padahal sebagian besar singkong dibudidayakan sendiri. Hal ini karena selama ini belum pernah dilakukan pelatihan maupun pendampingan tentang pengolahan singkong menjadi bahan baku olahan makanan yang lebih bervariasi.

\section{Tahap pelaksanaan}

Pada tahap pelaksanaan dilakukan praktek pengolahan singkong dan produk olahannya, yaitu:

\section{Tepung singkong}

Bahan-bahan yang digunakan terdiri atas : singkong segar $1 \mathrm{~kg}$, air bersih secukupnya untuk mencuci singkong segar, garam 5 g. Dari bahan-bahan ini dihasilkan sekitar 250-400 g tepung singkong yang selanjutnya dikemas dalam plastic kemasan yang telah disediakan sebelumnya. Masing-masing plastik diperuntukan untuk $1 \mathrm{~kg}$ tepung singkong (Cassava).

\section{Dodol Singkong}

Bahan-bahan yang digunakan terdiri atas tepung singkong $1 \mathrm{~kg}$, kelapa parut (santan) $1 \mathrm{~kg}$, gula merah $1 \mathrm{~kg}$, air dan garam secukupnya. Dari bahan-bahan ini dihasilkan 20 bungkus plastik, dimana berat masing-masing plastik berisi $100 \mathrm{~g}$ dodol singkong.

\section{Mie Cassava}

Bahan-bahan yang digunakan tepung singkong, tepung terigu, garam, kalium bikarbonat (pengenyal/pelentur mie), CMC, air dan minyak goreng secukupnya

Berdasarkan praktek pengolahan singkong menjadi bahan baku produk olahan makanan yang dilakukan ibu-ibu mitra/kelompok sasaran menunjukkan bahwa produk olahan makanan cukup berhasil hal ini dapat dilihat dari hasil olahan tepung singkongnya yang memiliki warna putih bersih dan bau yang khas demikian pula produk olahan lainnya seperti dodol singkong maupun mie cassava yang memiliki rasa enak, kenyal dan warna yang menarik.

\section{Tahap evaluasi akhir}

Setelah dilakukan kegiatan praktek pengolahan yang dilakukan oleh ibu-ibu mitra/kelompok sasaran selanjutnya dilakukan pengisian quisioner untuk mengevaluasi keberhasilan kegiatan seperti yang disajikan pada Tabel II.

Tabel II. Kuisioner dan jawaban setelah kegiatan

\begin{tabular}{|c|c|c|c|c|}
\hline No & Pertanyaan & \multicolumn{3}{|c|}{ Jawaban (\%) } \\
\hline 1. & $\begin{array}{l}\text { Apakah } \\
\text { penyuluhan } \\
\text { dan pelatihan } \\
\text { sudah jelas? }\end{array}$ & Sudah (100) & $\begin{array}{l}\text { Belum } \\
\quad(0)\end{array}$ & $\begin{array}{c}\text { Tidak } \\
\text { tahu }(0)\end{array}$ \\
\hline 2. & $\begin{array}{l}\text { Apakah } \\
\text { berminat } \\
\text { melakukan/ } \\
\text { mempraktekan } \\
\text { sendiri } \\
\text { dirumah? }\end{array}$ & Ya (100) & $\begin{array}{l}\text { Tidak } \\
(0)\end{array}$ & $\begin{array}{c}\text { Lainnya } \\
\text { (0) }\end{array}$ \\
\hline 3. & $\begin{array}{l}\text { Apakah } \\
\text { produk olahan } \\
\text { tepung } \\
\text { singkong } \\
\text { tersebut akan } \\
\text { dijual atau }\end{array}$ & $\begin{array}{l}\text { Dikonsumsi } \\
\text { sendiri (77) }\end{array}$ & $\begin{array}{l}\text { Dijual } \\
(23)\end{array}$ & $\begin{array}{c}\text { Lainnya } \\
\text { (0) }\end{array}$ \\
\hline
\end{tabular}




\begin{tabular}{|c|c|c|c|c|}
\hline 4. & $\begin{array}{l}\text { dikonsumsi } \\
\text { sendiri? } \\
\text { Produk olahan } \\
\text { tepung } \\
\text { singkong yang } \\
\text { mana paling } \\
\text { diminati untuk } \\
\text { dicoba? }\end{array}$ & $\begin{array}{l}\text { Dodol } \\
\text { singkong } \\
\text { (89) }\end{array}$ & $\begin{array}{c}\text { Mie } \\
\text { Cassava } \\
\text { (11) }\end{array}$ & $\begin{array}{l}\text { Lainnya } \\
\quad(0)\end{array}$ \\
\hline
\end{tabular}

Berdasarkan Tabel II menunjukkan bahwa ibu-ibu mitra/kelompok sasaran sudah jelas dengan materi yang disampaikan pada kegiatan pelatihan. Semua peserta turut berperan aktif mulai dari tahap awal kegiatan hingga tahap evaluasi akhir. Kemampuan menerima materi dan menerapkan keterampilan sudah cukup baik hal ini ditunjukkan dengan adanya minat untuk mencoba sendiri dirumah yang nantinya untuk dikonsumsi sendiri dan sebagian berminat untuk menjual produk olahan dari tepung singkong misalnya dodol singkong. Sebagian dari peserta juga memiliki ide untuk melakukan variasi aneka olahan kue modern seperti kue semprit, cake, dan brownies terhadap produk berbahan baku tepung singkong Beberapa keunggulan produk berbahan baku tepung singkong adalah selain dapat disimpan dalam waktu lama, juga dapat dijual dengan harga bersaing dengan tepung lainnya sehingga peluang usaha bagi ibu-ibu mitra/kelompok sasaran cukup terbuka lebar. Secara umum manfaat produk tepung singkong yang diolah dapat meningkatkan pendapatan dan nilai gizi masyarakat pada umunya dan kelompok ibu-ibu mitra pada khususnya di desa Tarung Manuah Kecamatan Basarang Kabupaten Kapuas. Bentuk program kegiatan ini juga secara tidak langsung turut membantu program pemerintah.

\section{KESIMPULAN}

Berdasarkan hasil kegiatan pengabdian kepada masyarakat yang dilaksanakan oleh perguruan tinggi Universitas Palangka Raya bersama mitra/kelompok sasaran di desa Tarung Manuah, kecamatan Basarang, kabupaten Kapuas dapat disimpulkan bahwa pelaksanaan kegiatan pemberdayaan masyarakat menunjukan adanya perkembangan hasil dari kondisi sebelum dan sesudah pelaksanaan kegiatan. Adanya kegiatan pelatihan/difusi ipteks dan pendampingan pengolahan singkong menjadi bahan baku produk olahan makanan yang dilakukan tentunya mampu memberikan kontribusi dan solusi untuk mengatasi permasalahan yang dihadapi mitra/kelompok sasaran. Adapun saran untuk kegiatan pengabdian selanjutnya adalah perlunya pembinaan lebih lanjut dari pihak terkait sehingga pengetahuan dan ketrampilan yang diperoleh dapat lebih bermanfaat dan menjadi alternatif usaha baru yang lebih berkesinambungan serta menghasilkan produk-produk inovasi baru yang lebih bervariasi.

\section{REFERENSI}

Atikah, T.A., Muliansyah, M., Widiarti, A., Rosawanti, P. 2019. Peningkatan Sains dan Kreativitas Masyarakat Melalui Budidaya Bawang Dayak Secara Organik dan Pengolahan Kompos Limbah Pasar Tradisional. PengabdianMu: Jurnal Imiah Pengabdian Kepada Masyarakat. 5(1):82-86.

https://doi.org/10.33084/pengabdianmu.v5i 1.1094

Badan Pusat Statistik Provinsi Kalimantan Tengah. 2019. Provinsi Kalimantan Tengah Dalam Angka 2019. Palangka Raya: Badan Pusat Statistik Provinsi Kalimantan Tengah.

Fardhayanti, D.S., Kusumaningtyas, R.D., Megawati, M., Hartanto, D. 2019. PKM Produksi Tepung Tapioka Maltodekstrin Dan Bioetanol Bagi Kelompok Tani Singkong. Amaliah : Jurnal Pengabdian kepada Masyarakat. 3(1):256-263. https://doi.org/10.32696/ajpkm.v3i1.237

Ginting, E. 2002. Teknologi Penanganan Pascapanen dan Pengolahan Ubikayu Menjadi Produk-Antara untuk Mendukung Agroindustri. Buletin Palawija. 2(4):67-83.

Mulyatun, M. 2019. Pemberdayaan Masyarakat Pesisir Berbasis Potensi Lokal; Alternatif Ketahanan Pangan Berupa Tepung Magrove. Dimas: 
Jurnal Pemikiran Agama untuk Pemberdayaan. 18(2):211-238.

https://doi.org/10.21580/dms.2018.182.3260

Muntoha, M. 2015. Pelatihan Pemanfaatan Dan Pengolahan Singkong Menjadi Makanan Ringan Tela Rasa. AJIE (Asian Journal of Innovation and Entrepreneurship). 4(3):149-154.

Nugraha, H.D., Suryanto, A., Nugroho, A. 2015. Kajian Potensi Produktivitas Ubikayu (Manihot esculenta Crant.) Di Kabupaten Pati. Jurnal Produksi Tanaman. 3(8):673-682.

Pemerintah Kabupaten Kapuas. 2017. Rencana Penyelenggaraan Infrastruktur Jangka Menengah Kabupaten Kapuas Tahun 2017-2021. Kuala Kapuas: Pemerintah Kabupaten Kapuas.

Rosmiati, M., Maulani, R.R., Dwiartama, A. 2018. Efisiensi Usaha Dan Nilai Tambah Pengolahan Ubi Kayu Menjadi Modified Cassava Flour (Mocaf) Pada Kelompok Wanita Tani Medal Asri, Desa Sukawangi Kecamatan Pamulihan Kabupaten Sumedang. 17(1):14-20. http://dx.doi.org/10.5614/sostek.itbj.2018.17. 1.2

Rukmana, R. 1997. Ubi Kayu, Budidaya dan Pasca Panen. Yogyakarta: Kanisius.

Santoso, I., Setiawan, B., Pranowo, D. 2015. The Application Of Processing Technology Of Assorted Chips For Optimizing Utilization Potential Local Resources. Journal of Innovation and Applied Technology. 1(1):95-100. http://dx.doi.org/10.21776/ub.jiat.2015.001.0 1.14

Sutama, I.K., Pugra, I.W., Arjana, I.W.B. 2015. Program IbM Dapat Mengubah Pandangan Masyarakat Selat Karangasem Terhadap Ubi Ungu. BHAKTI PERSADA: Jurnal Aplikasi Ipteks. 1(1):26-37. 